\title{
EDUCAÇÃO A DISTÂNCIA: TENSÕES ENTRE O PÚBLICO E O PRIVADO
}

JAIME GIOLO*

E ha natura sí malvagia e ria, Che mai non empie la bramosa voglia, E dopo 'l pasto ha piú fame che pria.

(Dante Alighieri)

RESUMO: O presente texto aborda a educação a distância (EaD) brasileira no contexto da expansão da educação superior, verificada depois da LDB/1996. O foco da análise são as ações avaliativas e regulatórias do Estado e o contraponto político da iniciativa privada, donde derivam três grandes tensionamentos, a saber: a prevalência do privado sobre o público; o problema da qualidade no binômio educação presencial versus educação a distância; e, finalmente, as controvérsias a respeito do modelo de EaD a ser assumido (ou não) pelo Brasil.

Palavras-chave: Educação a distância. Educação superior. Política educacional.

DisTANCE EDUCATION:

THE TENSIONS BETWEEN PUBLIC AND PRIVATE

ABSTRACT: This article discusses the Brazilian distance education in the context of expansion of higher education, observed after LDB/1996. The focus of this analysis is the evaluative and regulatory actions of state and political counterpoint of private enterprise,

Doutor em História e Filosofia da Educação e professor da Universidade de Passo Fundo (UPF-Rs).E-mail: giolo@uffs.edu.br

Educ. Soc., Campinas, v. 31, n. 113, p. 1271-1298, out.-dez. 2010

Disponível em <http://www.cedes.unicamp.br> 
whence derive three major tensions, which are: the attraction of private over public; the quality problem in the binomial presential education versus distance education; and, finally, the controversies regarding the distance education model to be assumed (or not) in Brazil.

Key words: Distance education. Higher education. Educational policy.

\section{Introdução}

7 bandeira da educação foi desfraldada, a todo o pano, na década de 1990. A Constituição Cidadã havia, pela primeira vez, definido o ensino fundamental como "direito público subjetivo" (art. 208, \$11) e o mundo inteiro estabelecia metas para expansão decidida da educação básica. ${ }^{1}$ A crise econômica e política do Brasil adiou um tanto essa arrancada, mas a segunda parte da década trouxe à luz, finalmente, a nova Lei de Diretrizes e Bases da Educação Nacional (Lei n. 9.394, de 20 de dezembro de 1996). No terreno do financiamento, o Fundo de Manutenção e Desenvolvimento do Ensino Fundamental e Valorização do Magistério (FUNDEF), criado pela Emenda Constitucional n. 14, de 12 de setembro de 1996, e regulamentado pela Lei n. 9.424, de 24 de dezembro de 1996, foi concebido para impulsionar, de forma inédita, o ensino obrigatório. O ensino médio ficou, de certa forma, esquecido, mas para a educação superior foi traçada uma política de expansão, dependente do capital privado (especialmente das mensalidades dos alunos).

Estabelecido o marco regulatório mínimo e preliminar (Lei n. 9.131, de 24 de novembro de 1995; LDB; Medida Provisória n. 1.477 39, de 8 de agosto de 1997, convertida na Lei n. 9.870, de 23 de novembro de 1999; Decreto n. 2.306, de 19 de agosto de 1997, Lei n. 9.649, de 27 de maio de 1998, Decreto n. 2.494, de 10 de fevereiro de 1998 etc.), ${ }^{2}$ a educação superior começou uma vertiginosa corrida expansionista. De acordo com o Censo da Educação Superior do Instituto Nacional de Estudos e Pesquisas Educacionais Anísio Teixeira (INEP), os números para instituições, cursos e matrículas presenciais, em 1996 (ano da publicação da LDB) e 2007, são os seguintes: 


\section{Gráfico 1}

Evolução das IES, cursos e matrículas presenciais da educação superior brasileira, com respectivos percentuais de crescimento - Brasil: 1996 e 2007

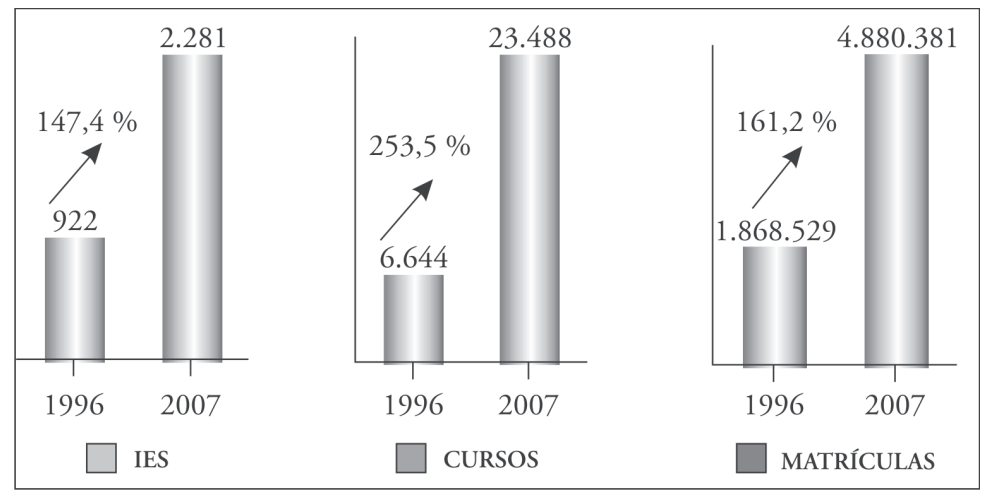

Fonte: MEC/INEP/Censo.

Embora muitos analistas, principalmente os ligados a instituições interessadas na expansão, tenham sobrevalorizado a existência de uma grande demanda por educação superior (e ela de fato existia, de forma que se passou de 1.868.529 matrículas presenciais, em 1996, para 4.880.381, em 2007), a verdade é que a oferta não obedeceu à demanda, sendo sistemática e progressivamente superior a esta (no gráfico 1, pode-se perceber que, enquanto o percentual de crescimento dos cursos foi de $253,5 \%$, as matrículas cresceram apenas $161,2 \%)$. Os dados referentes às vagas que permaneceram ociosas em cada processo seletivo são ainda mais convincentes. No gráfico 2, na próxima página, aparecem os percentuais de vagas não preenchidas na educação superior presencial, no geral, e para a educação privada, em específico.

A expansão da educação superior brasileira, no período pósLDB, foi, como se pode ver nos gráficos 1 e 2 , movida predominantemente pela oferta e isso acirrou sobremaneira a concorrência e a busca de formas alternativas de educação com o objetivo de atrair alunos. A flexibilização foi, pois, a palavra de ordem. Por meio dela, os currículos foram diversificados e enxugados; novos cursos mais breves, baratos e alinhados com as demandas imediatas e locais da clientela (os 
tecnológicos, ${ }^{3}$ especialmente) foram criados; e novas modalidades começaram a ser experimentadas (a EaD, sobretudo). A expansão privada da educação a distância precisa ser observada nesse contexto, pois, em essência, consiste numa estratégia de conquista de mercado.

\section{Gráfico 2}

Evolução das vagas não preenchidas nos processos seletivos, no geral, e em relação à iniciativa privada - Brasil: 2000-2007

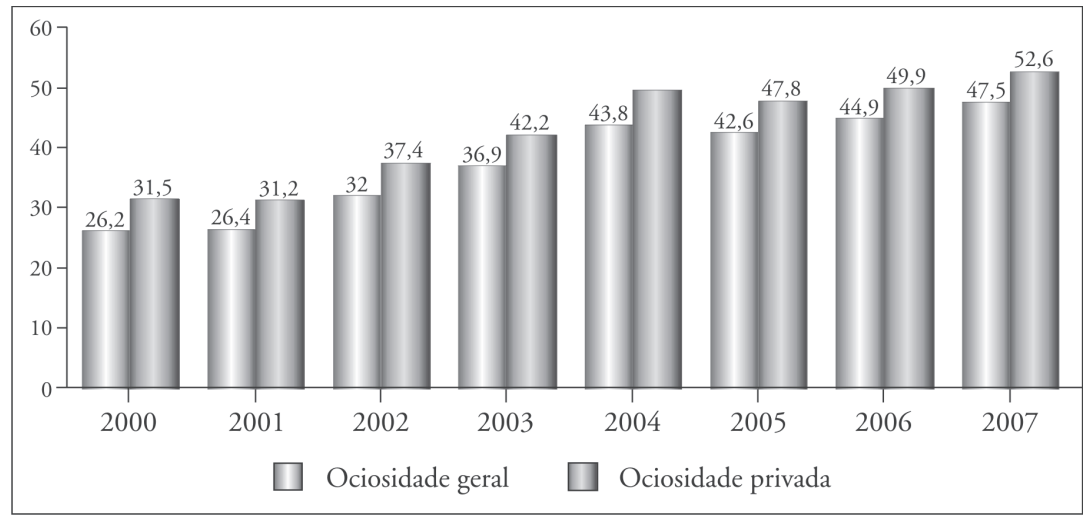

Fonte: MEC/INEP/CENSO

\section{O perfil da EaD no Brasil}

O equacionamento do ensino obrigatório, no Brasil, não poderia ocorrer sem considerar o elemento docente. Havia um exército de professores sem formação adequada, especialmente os que atuavam em lugares tradicionalmente esquecidos pelas políticas públicas e pelo desenvolvimento econômico. Como atingi-los rápida e massivamente? É em função disso que foram feitos, por parte do Estado, os primeiros movimentos para implantar redes de educação a distância. Em 1995, o governo federal criou uma Subsecretaria de EaD, no âmbito da Secretaria de Comunicação da Presidência da República, em seguida incorporada pela Secretaria de Educação a Distância do Ministério da Educação, criada em 1996. Com o objetivo de usar tecnologias avançadas para dar suporte à 
educação básica, foram implantados o Programa de Apoio Tecnológico à Escola, o Programa Nacional de Informática na Educação (PROINFO) e a TV Escola, entre 1995 e 1996. Essas ações estavam voltadas essencialmente para dar suporte às aulas presenciais. Em seguida, começaram a ser montados, pelas instituições públicas, programas de formação de professores: formação continuada e, principalmente, programas destinados a titular professores leigos. As indicações da LDB de que a educação básica deveria ser ministrada por professores formados em nível de graduação (LDB, art. 62 e art. 87, $\$ 41$ ), por um lado, e o FUNDEF, destinando recursos para a capacitação dos profissionais do magistério, por outro, acabaram incentivando o envolvimento das instituições de educação superior oficiais com a EaD.

O uso do cachimbo entorta a boca. A iniciativa privada, quando entrou no jogo, vencendo as resistências do poder público quanto ao credenciamento de IES para a oferta de cursos a distância, ${ }^{4}$ privilegiou exatamente a área de formação de professores: especialmente Pedagogia e Normal Superior. ${ }^{5}$ A abertura de perspectivas para outras áreas se fez na sequência, especialmente no campo da Administração e Serviço Social, mas as licenciaturas ainda permanecem como campo privilegiado. No Censo de Educação Superior do INEP, a iniciativa privada começou a aparecer com alunos matriculados em EaD, apenas, no ano de 2002 e, desde então, seu crescimento foi espetacular, como pode ser observado no gráfico 3. Sobre esse gráfico é preciso considerar o seguinte: a UNITINS, embora fosse uma instituição estadual, sempre cobrou mensalidades nos cursos que oferecia (motivo, inclusive, por que sofreu uma intervenção do MEC, como se verá). Por isso, suas matrículas foram contadas no campo privado.

Especialmente impulsionada pela iniciativa privada, a educação a distância expandiu-se sem cessar e em índices altíssimos. Os gráficos 4 e 5 mostram a evolução dos cursos e das matrículas em EaD no Brasil.

O quadro 1, após os gráficos, retrata, com dados de 2007, as áreas preferidas para investimento em EaD. No que se refere à graduação, os interesses, como já foi assinalado, estão bastante concentrados na formação de professores, Administração e Gestão, Serviço Social e Ciências Contábeis. Juntas, essas áreas detêm 97,3\% das matrículas. 
Educação a distância: tensões entre o público e o privado

\section{Gráfico 3}

Distribuição percentual da EaD, por categoria administrativa - Brasil: 2000-2007

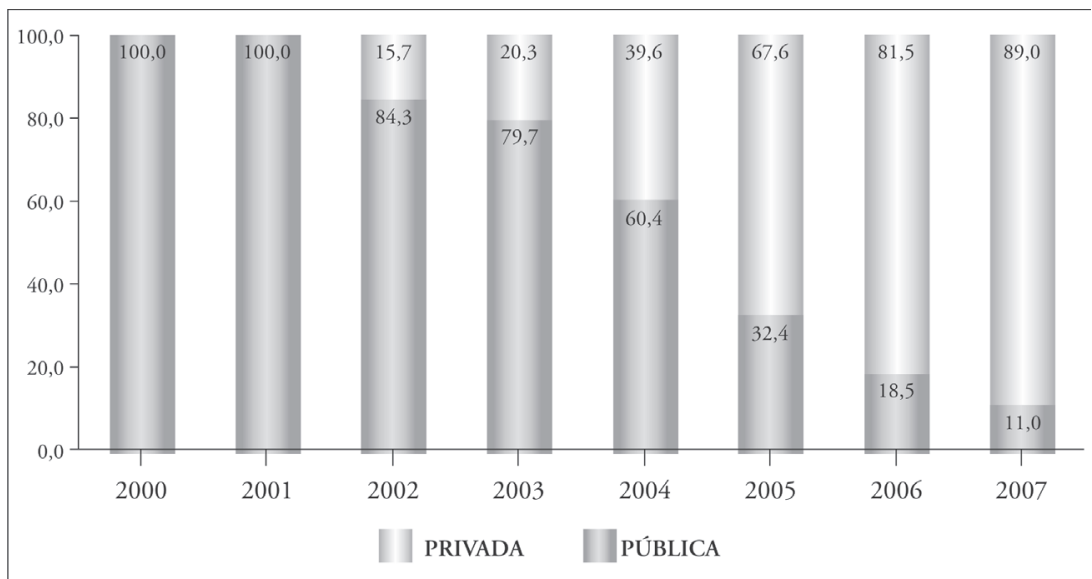

Fonte: MEC/INEP/Censo

\section{Gráfico 4}

Evolução dos cursos de EaD - Brasil: 2000-2007

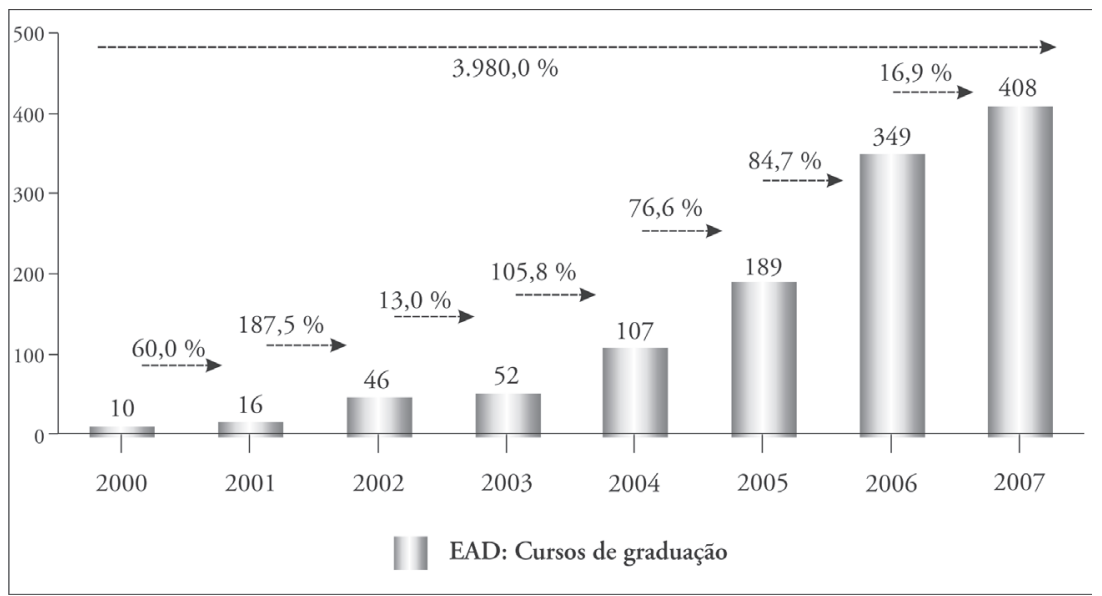

Fonte: MEC/INEP/Censo. 


\section{Gráfico 5}

Evolução das matrículas de EaD - Brasil: 2000-2007

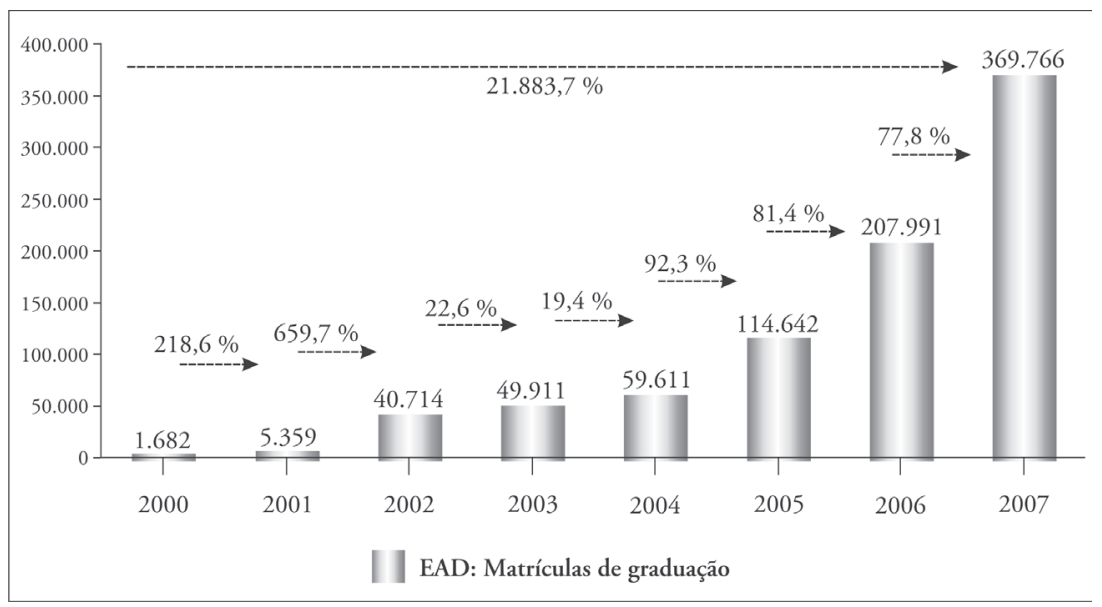

Fonte: MEC/INEP/Censo.

\section{Quadro 1}

\begin{tabular}{|c|c|c|c|}
\hline \multicolumn{4}{|c|}{ ÁREAS DE PREDILEÇÃO DA EaD - MATRÍCULAS DE 2007} \\
\hline \multicolumn{2}{|l|}{ Licenciaturas } & 215.703 & $58,3 \%$ \\
\hline Pedagogia e Normal Superior & 155.431 & & \\
\hline Letras & 25.795 & & \\
\hline Matemática & 10964 & & \\
\hline Biologia & 6.916 & & \\
\hline História & 5.569 & & \\
\hline \multicolumn{2}{|l|}{ Administração/Gestão } & 100.879 & $27,3 \%$ \\
\hline Administração & 40.101 & & \\
\hline Competências Gerenciais & 33.460 & & \\
\hline Marketing & 8.456 & & \\
\hline \multicolumn{2}{|l|}{ Serviço Social } & 31.115 & $8,4 \%$ \\
\hline \multicolumn{2}{|l|}{ Ciências Contábeis } & 12.165 & $3,3 \%$ \\
\hline \multicolumn{2}{|l|}{ Total } & 359.862 & $97,3 \%$ \\
\hline \multicolumn{2}{|l|}{ Total Geral } & 369.766 & $100,0 \%$ \\
\hline
\end{tabular}

Fonte: MEC/INEP/Censo

Educ. Soc., Campinas, v. 31, n. 113, p. 1271-1298, out.-dez. 2010

Disponível em <http://www.cedes.unicamp.br> 
Importa analisar e meditar sobre a ação da EaD nas licenciaturas $(58,3 \%$ das matrículas, em 2007) e, de modo especial, nos cursos de Pedagogia e Normal Superior. Nesses dois cursos, a participação da EaD é tão expressiva que já detém 32,1\% de todos os alunos. Repetindo, em outras palavras: dos alunos que, em 2007, se preparavam para o exercício do magistério na educação infantil e nos anos iniciais do ensino fundamental, um terço deles fazia-o em cursos a distância. Em seguida, vêm os cursos de Letras e Matemática, nos quais $13,8 \%$ e $13,2 \%$, respectivamente, dos alunos matriculados estão estudando a distância. Fora das licenciaturas, grande impacto, talvez o mais radical até o momento, recebeu o curso de Serviço Social. No Censo da Educação Superior do INEP, este curso, na modalidade a distância, aparece, pela primeira vez, em 2007 e, mesmo assim, já abocanhou $37,1 \%$ das matrículas daquele curso. Nos casos da Pedagogia e do Serviço Social, há claros sinais de que sua expansão a distância esteja se dando em detrimento do ensino presencial. É de se perguntar se isso é adequado para o Brasil.

\section{A ação política em favor da EaD}

Os interesses privados nunca foram meros expectadores da política educacional, muito menos no período recente. Enquanto o poder público formulava propostas para titular docentes (buscando atender ao disposto na LDB) e auxiliar, a distância, os professores que atuavam presencialmente, envoltos em toda a sorte de dificuldades, a iniciativa privada foi montando suas trincheiras de disputa política. No Centro de Convenções do Anhembi, em São Paulo, em 21 de junho de 1995, foi criada a Associação Brasileira de Educação a Distância (ABED), uma "sociedade científica, sem fins lucrativos, que tem como finalidades promover o estudo, a pesquisa, o desenvolvimento, a promoção e a divulgação da Educação a Distância”. ${ }^{6}$ Em que pesem suas incursões no terreno da pesquisa e na troca de experiências, o foco central da ação da ABED sempre foi a política.

$\mathrm{Na}$ Assembléia Geral da Entidade, em 1996, foi aprovado um documento com nome exótico de I Epistola de São Paulo sobre Educação a Distância. Nessa Epístola, feita em forma de recomendaçōes, aparece muito claramente sua posição militante em termos de conquista de espaço para a EaD. Diz a recomendação número 3: "Buscar 
adequar a legislação educacional brasileira às características específicas da educação a distância”. O diagnóstico da legislação existente não pareceu nada favorável: "A legislação educacional brasileira, além de não incentivar a educação a distância, cria dificuldades para sua aplicação, em geral, submetendo a às mesmas exigências que se aplicam ao ensino presencial". Por isso, a recomendação 3 identifica a

(...) necessidade de se criar uma boa articulação, junto às autoridades educacionais, com vistas a: a) eliminar as restriçõos hoje existentes em relação à educação a distância, que deve receber o mesmo tratamento dispensado ao ensino presencial; b) desenvolver programas de educação a distância em nível regional e nacional sem a obrigatoriedade de prévia autorização dos sistemas de ensino dos estados; c) assessorar o Congresso Nacional, os conselhos estaduais de Educação e o CONSED - Conselho de Secretários Estaduais de Educação, na tarefa de regulamentar a educação a distância.?

O contexto dessa recomendação epistolar foi o debate que precedeu a aprovação da LDB pelo Congresso Nacional. O próximo round seria a regulamentação do artigo 80 .

Em 1998, a ABED produziu a II Epistola de São Paulo sobre Educação a Distância, na qual as linhas de ação se dirigem à regulamentação do artigo 80 da LDB e à confecção do Plano Nacional de Educação. Diz o documento:

A despeito da atuação cuidadosa da SEED - Secretaria de Educação a Distância do MEC, com a colaboração permanente da ABED e de outras entidades atuantes na área, procurando assessorar a regulamentação do artigo 80 da Lei de Diretrizes e Bases da Educação, que trata da educação a distância e do capítulo do Plano Nacional de Educação referente a essa área, persiste a necessidade de uma ampla campanha de esclarecimento junto às lideranças políticas, educacionais, agências financiadoras, formadores de opinião e à sociedade em geral, sobre as características da educação a distância e as vantagens de sua utilização. ${ }^{8}$

Possivelmente em 2000, a ABED produziu a Epistola de São Sebastião sobre Educação a Distância, prometendo redobrar a ação política. $\mathrm{Na}$ recomendação 2, o documento considera ser necessário "rever e avaliar as estratégias referentes ao encaminhamento das questôes evidenciadas pelas Epístolas I e II de São Paulo e adotar atuação mais proativa, que inclua ação conjunta com outras sociedades científicas 
congêneres, visando contribuir mais efetivamente para a formulação de políticas educacionais". ${ }^{9}$ Em agosto de 2001, na Assembléia Geral da entidade, o assunto voltou à pauta. A Ata dessa Assembléia registra as intervenções de associados, reivindicando "um acompanhamento maior pela ABED do aspecto legal e dos posicionamentos de autoridades públicas sobre a questão educação a distância”. A entidade deve pronunciar-se sobre as "questões legais que estão sendo encaminhadas pelos órgãos públicos e que determinam o rumo das políticas educacionais do país relacionadas à educação a distância”. As questões técnicas da EaD estão na dependência das questôes políticas, por isso a diretoria deve mover "ações políticas e, se necessário, ações jurídicas frente a questões controversas relacionadas a EaD” Compete à $A B E D$ "aplaudir o poder público quando ele toma posições corretas mas, também, a assumir seu papel de órgão questionador quando as ações governamentais não forem adequadas". Houve, inclusive, a indicação para que fosse criada pela ABED uma Diretoria de Assuntos Jurídicos para cuidar desses temas. O presidente da entidade reforçou as teses dos associados e anunciou a Carta de Dom Bosco, que "se configurará como um posicionamento da ABED frente às questões políticas que atualmente se apresentam". ${ }^{10}$

Com o tempo, a ABED só fez incrementar suas posições. Em 2009, ela publicou um extenso livro: Educação a distância: o estado da arte, organizado pelo seu presidente, Fredric Litto, e pelo vice-presidente Marcos Formiga. Na tradição e na sequência das Epistolas, esse livro bem que poderia ser chamado de $A$ Bíblia. À parte as informações de cunho teórico e técnico sobre a educação a distância, o livro é também um instrumento de combate político. Em vários momentos, ao longo da obra, isso pode ser observado, principalmente no texto de Bermardo Kipnis, professor da Universidade de Brasília e coordenador do projeto Global Development Learning Network, em parceria com o Banco Mundial. Referindo-se a um texto de Fredric Litto, ainda não publicado, diz:

Especificamente para o Brasil, com tradição europeia na educação superior e colonização patrimonialista portuguesa, a tendência para centralização do controle e a necessidade do estabelecimento de uma legislação detalhista a ser seguida impõe uma "camisa de força", principalmente às iniciativas inovadoras. No caso da EaD, apesar dos avanços conquistados, 
corre-se o risco de paralisação de um processo cuja dinâmica, principalmente tecnológica, requer a máxima flexibilidade possível, deixando para os indivíduos julgarem os resultados alcançados, e uma legislação apenas direcionadora, com princípios mais gerais. (Kipnis, 2009, p. 212)

A ABED não está sozinha na luta política para conquistar espaços legais e institucionais para a EaD. Talvez mais decisiva e mais importante do que qualquer outra iniciativa tenha sido a formação, no âmbito do Congresso Nacional, de uma Frente Parlamentar. Com efeito, em 14 de setembro de 1999, foi instituída a Frente Parlamentar de Apoio à Educação a Distância, integrando 62 deputados e 2 senadores, pertencentes a 13 partidos (predominância do PFL, com 20 parlamentares; do PMDB, com 11; e do PSDB, com 8) e abrangendo 22 Estados e o Distrito Federal (predominância de sP, com 7 parlamentares; MG, com 6; e RS, SC e PR, com 5). A Frente é uma "entidade de direito privado, constituída por representantes de todas as correntes de opinião política do Congresso Nacional, podendo ter representações nas Assembléias Legislativas Estaduais e na Câmara Legislativa do Distrito Federal". Seu objetivo é "estimular a ampliação de vagas nas escolas e instituições de ensino superior no Brasil, especialmente com a utilização dos meios eletrônicos como a Telemática". ${ }^{11}$ Entre as suas finalidades estão as de

(...) acompanhar a política oficial de educação nacional relacionada com a Educação a Distância, manifestando se quanto aos aspectos mais importantes de sua aplicabilidade, (...) procurar, de modo contínuo, o aperfeiçoamento da legislação referente à Educação a Distância, influindo no processo legislativo a partir das comissões temáticas nas duas Casas do Congresso Nacional [e] (...) apoiar as instituições interessadas na aplicação da Educação a Distância, junto a todos os Poderes, inclusive em questōes orçamentárias nos casos das entidades públicas. ${ }^{12}$

Uma e outra dessas instituiçôes, junto com as demais que tocam a mesma música, defendem a máxima flexibilização e reivindicam para o Estado um papel apenas direcionador e estimulador. Nada de estruturas rígidas de avaliação e controle. A eficácia dessa artilharia não foi nada desprezível. A tímida regulamentação (fundamentalmente, o Decreto n. 2.494, de 10 de fevereiro de 1998, e o Decreto n. 5.622, de 19 de dezembro de 2005), que antecedeu à normatização de 2007, carrega traços genéticos que lhe acusam certo 
Educação a distância: tensões entre o público e o privado

grau de parentesco com as teses defendidas pela ABED e pela Frente Parlamentar. O melhor dos mundos para a iniciativa privada.

As tensões entre o público e o privado

O terreno da EaD e o seu entorno estão repletos de tensões de natureza e intensidade variáveis. Esquematicamente, se podem visualizar três variantes principais: (1) as geradas pela prevalência do privado sobre o público; (2) as geradas pelas tentativas de controle da qualidade; e (3) as geradas pela tendência de definição de um modelo de EaD para o Brasil.

\section{A prevalência do privado sobre o público}

O universo privado passou a exercer uma extraordinária sedução sobre o setor público, sobretudo quando a política educacional brasileira optou por incentivar parcerias público-privadas e sugerir às (quase a exigir das) instituições de educação superior a captação de recursos externos, por meio de projetos de pesquisa, desenvolvimento, extensão etc. Esse processo foi sobremaneira forte ao longo da década de 1990. Nesse período, o setor público padecia de carências de toda a ordem e o setor privado parecia oferecer compensações extraordinárias. $\mathrm{O}$ efeito mais expressivo dessa política foi, certamente, a montagem de uma malha de fundações privadas que circunscreveram completamente as principais universidades públicas brasileiras. Já no início do novo milênio, a Associação dos Docentes da Universidade de São Paulo fazia este alerta: "A proliferação das fundações de direito privado no interior da USP assume tal proporção atualmente que se pode afirmar, sem risco de erro, que a universidade está parcialmente privatizada”. ${ }^{13}$ A privatização não consiste tanto na dependência que as universidades passaram a ter do capital privado, mas, principalmente, na administração privada de recursos públicos que essas fundações amealham, por meio de convênios ou contratos (muitos obtidos por dispensa de licitação) feitos com órgãos do Estado. O prof. Ciro Teixeira Corrêa, presidente da ADUSP, denunciou, em 2001, perante a Comissão de Educação da Assembléia Legislativa de São Paulo, que, no que concerne às Fundações da UsP, "em média, cada docente recebe $\mathrm{R} \$ 145 \mathrm{mil}$ por ano, o que corresponde a cerca 
de $\mathrm{R} \$ 10$ mil por mês, ou seja, o dobro do salário normal de um docente". ${ }^{14}$

Em proporções variadas, o que foi observado em relação à USP vale para as demais instituições públicas. Pesquisas, consultorias, treinamentos, cursos (especialmente os de pós-graduação lato sensu) e outros serviços passaram a ser negociados por instituiçôes (por meios das fundaçôes ou de outras instâncias) e professores públicos, seguindo princípios que caracterizam mais propriamente as regras do mercado do que as regras do Estado. A educação a distância não tardou a fazer parte desse tipo de atividade. Foi perceptível a movimentação de certos setores que vivem no seio das instituições públicas, no sentido de criar arranjos que lhe permitissem (e/ou a alguns de seus profissionais) faturar um dinheiro extra por conta da EaD. Houve casos em que instituições inteiras apostaram muitas fichas na venda de cursos a distância. São paradigmáticas as aventuras da Universidade do Estado de Santa Catarina (UDESC) e da Universidade do Tocantins (UNITINS).

A UDESC foi uma das primeiras instituições de educação superior a ofertar cursos de graduação a distância. ${ }^{15}$ Ela construiu parcerias com municípios e outras instituiçôes educacionais (como a Sociedade Educacional de Capivari de Baixo), de quem recebia certos valores pela oferta do curso de pedagogia a distância. As entidades parceiras cobravam dos alunos. Não demorou muito para que os ex-alunos começassem a entrar na justiça requerendo a devolução das mensalidades cobradas, sob a alegação de que essa prática fere o artigo 206, IV da Constituição Federal. A Justiça está dando ganho de causa aos alunos e condenando a UDESC e as entidades parceiras a restituírem os valores cobrados aos demandantes. $\mathrm{O}$ teor de uma dessas decisōes diz:

Não é muito difícil antever se que, na verdade, quem está cobrando dos alunos é a UDESC, valendo se da entidade contratante. Uma forma pouco sutil de se desviar da proibição legal de manter cursos mediante contraprestação. Os documentos colacionados aos autos demonstram de forma inquestionável que os autores são alunos da UDESC no Curso de Graduação em Pedagogia a Distância, o qual é ministrado por meio de prepostos ou tutores. Também é incontroverso que para participar do citado Curso estão sendo cobradas, mesmo que por interposta pessoa, prestaçôes mensais. (...) Pela restituição das mensalidades indevidamente cobradas 
respondem, solidariamente, o estabelecimento oficial de ensino e as entidades conveniadas, públicas ou privadas. ${ }^{16}$

Nessa mesma linha, O Portal de Canoinhas, no final de 2008, trouxe a notícia de que Justiça da Comarca de Canoinhas condenou a Prefeitura de Três Barras e a UDESC a devolver, a alunos do curso de Pedagogia a distância, os valores pagos a título de mensalidade. Em anos anteriores, a Prefeitura de Três Barras, por meio de convênio com a UDESC, ofereceu o curso de Pedagogia a distância, cobrando mensalidades. Alguns alunos ingressaram com ação da Justiça, alegando que a UDESC é uma universidade pública, financiada com recursos do governo do Estado, e, por isso, não poderia cobrar mensalidades pela oferta de seus cursos. A Justiça acatou a ação, declarando indevidos os pagamentos efetuados pelos alunos. A Prefeitura e a UDESC, de forma solidária, foram condenadas a restituir aos autores os valores pagos, com juros e correção monetária. ${ }^{17}$

A unitins fez algo semelhante. Criada em 1990, na forma de autarquia estadual, a instituição sofreu, nos anos subsequentes, várias reformulações, deixando, inclusive, de ser autarquia para tornar-se fundação pública de direito privado. A reformulação mais radical aconteceu em 2000, quanto transferiu parte de seu patrimônio e os cursos regulares para a recém-criada Universidade Federal do Tocantins (UFT). Daí para frente, ocupou-se, fundamentalmente, de educação a distância. ${ }^{18}$ Para isso, fez parcerias com a Secretaria Estadual de Educação, Secretarias Municipais de Educação, Fundação Educacional do Bico do Papagaio e com a Sociedade Civil de Educação Continuada (EADCON), por intermédio das quais, e operando com EaD, matriculou um enorme número de alunos, espalhados pelos quadrantes do Brasil. No Censo da Educação Superior do InEP, a UnITINS aparece, em 2005, com 15.974 matrículas e chega, em 2007, a 51.997 matrículas.

Essa expansão se deu, como não poderia deixar de ser, pelas regras da iniciativa privada, ou seja, pela venda de projetos e pela cobrança de mensalidades. Como se trata de uma instituição pública, fere com essa prática o artigo 2006, IV da Constituição Federal, o que levou o Ministério Público Federal no Estado do Tocantins, ainda em 2004, a instaurar o Procedimento Administrativo n. 1.36.000.000999/2004 11. Essa e outras irregularidades, 
apontadas pela Coordenação Geral de Supervisão da Secretaria de Educação a Distância (SEED), ${ }^{19}$ ensejaram o Despacho do Secretário de Educação a Distância, de 25 de fevereiro de $2009,{ }^{20}$ suspendendo processos seletivos e ingressos de novos estudantes nos cursos de graduação a distância. Mediante a alegação da UNITINs de que não poderia conceder gratuidade a todos os alunos, foi assinado um Termo de Ajuste de Conduta entre o Ministério da Educação e a UFT, com a interveniência do Ministério Público Federal do Tocantins, no qual a UNITINS se compromete a transferir os alunos para outras instituiçōes de educação superior em situação regular, perante as normas do sistema federal de educação.

As ações do Ministério da Educação e do Ministério Público, por um lado, e a implantação da Universidade Aberta do Brasil (UAB), por outro, estão corrigindo esses descaminhos. A UAB é uma forma essencialmente pública de operar educação a distância, seguindo os caminhos normais das instituiçôes públicas, ou seja, financiada pelos recursos do Estado e oferecida gratuitamente à população. Não toma atalhos. Além de coordenar e conferir organicidade às ações de EaD das instituições federais de educação, deverá servir de parâmetro para as demais instituiçóes oficiais que atuam ou pretendem atuar com educação a distância.

\section{O problema da qualidade}

A educação superior pública (especialmente a federal e de várias instituições estaduais) manteve, desde o começo de sua história, propostas de excelência. Os investimentos, embora oscilantes, possibilitaram que essas instituiçôes mantivessem esse status, mesmo porque, como organismos estatais, elas sempre mantiveram muita presença (humana e política) nas esferas do governo. Inclusive o seu posicionamento geográfico (capitais e cidades mais importantes), aliado a um processo seletivo rigoroso (possibilitado pela expressiva demanda), ajudou a conferir-lhe um caráter de elite. Foram montadas estruturas acadêmicas sólidas, servidas por professores altamente qualificados e trabalhando em tempo integral, que dialogam com o conhecimento de ponta, seja nacional ou internacional. A alma e o corpo da pós-graduação stricto sensu do Brasil estão assentados nessa estrutura. $\mathrm{O}$ espírito acadêmico público se considera (e é de fato, em 
grande medida) o guardador de lugar da qualidade do ensino, da pesquisa e da extensão. Não é exclusivo, porém. É preciso reconhecer um conjunto de instituições privadas (especialmente, as grandes confessionais e comunitárias, mas há também particulares) que presta significativas contribuições à qualidade da educação superior. Não é sem razão, portanto, que, desse universo, surjam questionamentos toda vez que se formulam propostas flexíveis e aligeiradas de educação. Com a educação a distância não é diferente. Para quem considera a relação ensino-aprendizagem sob o ponto de vista das múltiplas facetas que a conformam e percebe a densidade do intercâmbio presencial, parece-lhe caricata a proposta de fazer isso a distância.

Essas preocupações acabaram por gerar consequências nas ações avaliativas e regulatórias do MEC, que, nos últimos anos (fundamentalmente, depois de 2007) se tornaram mais efetivas e propositivas. Tal fato mereceu a reação pronta da ABED que, em novembro de 2008, publicou, na pessoa de seu presidente, Fredric Litto, um texto estruturado em 10 pontos, nos quais analisa e questiona a posição do MEC. Escreve o presidente: "A ABED, desde sua fundação, em 1995, vem defendendo a ideia de que é contraproducente assumir que qualidade (no binômio ensino/aprendizagem) seja monopólio de instituiçôes públicas - há exemplos de excelência e de mediocridade em ambos os universos, no convencional ou a distância” (Litto, 2008). Essa afirmação, embora pareça relembrar uma verdade singela - a de que há problemas e méritos quanto à qualidade, tanto no universo público quanto no privado -, quer, no mínimo, dizer que o poder público, com suas instituições avaliadoras, regulatórias e educacionais, não tem o direito de interferir na iniciativa privada. Essa é a verdadeira tese, sempre reiterada, como ainda se verá no próximo tópico deste texto.

Os defensores da educação a distância sustentam não haver estudos científicos abrangentes que mostrem que esta modalidade é de menor qualidade do que a presencial. Por isso, a educação a distância deveria ter o apoio e a liberdade requeridos por seus líderes. Eles, entretanto, se esquecem de considerar que esse argumento vale, igualmente, para a tese contrária. Como não temos esses tais estudos científicos, manda a prudência que o andor siga vagarosamente, pois o santo pode ser de barro. Esse é um ponto central e para o qual se deve prestar a máxima atenção, especialmente naquilo que se refere 
aos cursos de graduação, onde a experiência brasileira com EaD tem, no máximo, uma década. Costuma-se localizar a gênese da EaD, entre nós, no início do século $\mathrm{xx}$, havendo, inclusive, quem a coloque já no século XIX, e com isso tenta-se justificar a sua maturidade e, principalmente, o direito de ela operar livremente. Esse passado não serve, em nada, para os propósitos que se tem em mente, pois consiste numa história de ensino não escolar e cujos resultados nunca foram adequadamente avaliados, tão inexpressivos foram para a elevação cultural, científica e tecnológica do país. A educação a distância como substituta da educação escolar é posterior à LDB de 1996 e, na maioria dos casos, é fruto do século XXI. São plenamente justificáveis, portanto, os cuidados dos poderes públicos e as objeções da academia.

O problema, entretanto não é apenas esse. Não se trata somente de conferir se a educação a distância consegue ser igual à presencial naquilo que se propõe a fazer. Posto que, nesse terreno, há ainda muito para ser analisado e sopesado, existe outro ponto que precisa ser esclarecido: o que a educação a distância se propõe a fazer é tudo o que se deve esperar de um processo educacional? Essa face da moeda é tão importante quanto a outra. A esse respeito, diz Fredric Litto:

Seja na convencional opção presencial, seja na modalidade a distância, os critérios de qualidade no ensino superior devem ser iguais, levando o aluno aos mesmos propósitos: usar a informação com inteligência, aplicar o conhecimento adquirido na disciplina escolhida e em outras áreas, desenvolver espírito crítico e realizar pesquisa, além de comunicar se com clareza. $^{21}$

Esses propósitos (usar inteligentemente a informação, aplicar o conhecimento, desenvolver o espírito crítico, pesquisar e comunicar com clareza) são tudo o que se pode e se deve esperar da educação? De que educação e, principalmente, de que educando se está falando? Em se tratando de educação continuada, onde o objetivo principal é o aperfeiçoamento técnico das pessoas (geralmente adultos profissionalizados), esses propósitos talvez sejam suficientes. Entretanto, se o enfoque for os cursos de graduação, frequentados principalmente por jovens entre 18 e 24 anos, o assunto assumirá outras proporções. Nesse caso, é preciso perceber que o destinatário da educação superior está realizando um autêntico rito de passagem: o processo no qual se abre 
para a vida adulta, ou seja, no qual tem de começar a encarar, autonomamente, a profissão, o casamento, a sociedade, a política, a ética, a estética, o futuro. Para isso, não bastam propósitos técnicos; além desses, são necessários propósitos filosóficos, para resumir tudo numa palavra. Note-se que é decisivo para o jovem compreender, inclusive a profissão, para além de seu aspecto técnico; ela é, acima de tudo, uma atividade social, com todas as implicâncias que esse qualificativo lhe confere. O campus universitário, entendido como espaço social (de diálogo, de disputa, de troca de experiência e, principalmente, de contato com a cultura elaborada) torna-se essencial e não mero assessório, como está subjacente na filosofia da EaD. Talvez seja por isso que nenhum tratado de EaD aborde o tema do movimento estudantil e do engajamento sócio-político do estudante como parte de sua formação. ${ }^{22}$

O problema é tão grande que não é possível escondê-lo completamente. Muitos trabalhos sobre EaD destacam a interatividade, como sendo o "Rubicão" que é preciso transpor. Um tanto sem jeito, começa-se a estudar o conceito de interação nos clássicos da pedagogia e da psicologia, como, por exemplo, Piaget e Vygotsky, embora o principal das referências teóricas em EaD ainda seja constituído por textos técnicos provindos da informática, da engenharia de software, da economia e da comunicação, principalmente norte-americanos. $\mathrm{O}$ conceito mesmo de interação permanece ainda caricato. No geral, supóe-se que a troca de informaçôes, por meio virtual, seja exatamente igual à atividade coletiva propriamente dita. Será? Hic Rhodus, hic salta!

\section{Controvérsias a respeito do modelo de EaD}

A moldura ampla, dentro da qual se estabelece a tensão institucional, é constituída pela ideologia neoliberal que, nos últimos anos, fez o discurso da emancipação da sociedade civil em relação ao Estado. É um jogo, ao mesmo tempo, confuso e pesado. Confuso porque o termo sociedade civil é polissêmico, cabendo, dentro dele, desde os representantes do capital internacional (interessados em descaracterizar completamente a instituição Estado) até os representantes dos setores populares (via de regra, interessados em fortalecer o Estado e, junto a ele, buscar proteção e oportunidades). O mesmo acontece com o termo Estado, estrutura que integra, nos seus quadros, agentes que 
operam segundo os interesses públicos e agentes que instrumentalizam o aparelho em proveito da iniciativa privada. É um jogo pesado porque não se resume a um confronto de ideias, mas carrega, no subsolo, forças econômicas de grandes proporções, capazes de plastificar a política de alto a baixo e moldá-la segundo a conveniência de interesses nem sempre confessáveis. De qualquer forma, há elementos dessa disputa que são confessados e, por isso, se pode traçarlhe um esquemático mapa.

No que se refere à educação a distância, de um lado, opera o Estado, formulando políticas, regulamentos e instrumentos que possibilitem avaliar e controlar as iniciativas das instituições de educação superior; de outro, certas instituições de educação superior e as entidades que as representam ou defendem seus interesses. Essas entidades aumentaram, nos últimos anos, o ânimo de seu combate, motivadas principalmente pelo endurecimento do Ministério da Educação. A já referida normatização de 2007 (Portaria Normativa n. 2, de 10 de janeiro de 2007, subsumida e revogada pela Portaria n. 40, de 12 de dezembro de 2007, que instruiu o processo de avaliação da EaD, Portarias n. 1.047 , n. 1.050 e n. 1.051 , de 7 de novembro de 2007, que dotam o INEP de instrumentos de avaliação de Instituições, polos e cursos de EaD, e o Decreto n. 6.303, de 12 de dezembro de 2007, que regulamenta processos de avaliação e regulação do Ministério da Educação) fez parecer aos olhos da iniciativa privada a institucionalização de um modelo de EaD para o Brasil. Esse modelo é um dos pomos da discórdia.

Por ocasião do lançamento dos instrumentos de avaliação da educação a distância, o secretário da SEED, Carlos Eduardo Bielschowsky, prevendo o conflito, adiantou: "O MEC não está fechado em um único modelo de educação a distância, mas propõe diretrizes”. ${ }^{23}$ Essas diretrizes, materializadas nos instrumentos de avaliação que exigem polos claramente constituídos como espaços escolares e o cumprimento de uma série de regras por parte das instituições, inclusive a de proporcionar aos alunos momentos presenciais, não deixa de ser uma ação modeladora. A ABED considera que isso significa bloquear a criatividade, ao mesmo tempo em que se traduz na assunção de um modelo exclusivo para a EaD no Brasil. O ministro da Educação, em matéria publicada pela Folha de S. Paulo, em 2008, não temeu em assumir o modelo e reafirmar a posição reguladora do Estado. Disse que o MEC 
Educação a distância: tensões entre o público e o privado

continuará rigoroso com a criação de cursos a distância e reafirmou a diretriz de que os polos sejam dotados de bibliotecas e mantenham atividades presenciais. O ministro chegou a sugerir $20 \%$ das atividades presenciais. "Nosso modelo não é de educação 100\% virtual", afirmou. ${ }^{24}$

Em novembro de 2008, o presidente da ABED, Fredric Litto, no documento, já citado, que assinou em nome da Associação, interpreta a intenção do Ministério e contesta o modelo único. Escreveu Litto:

Acreditamos que o MEC esteja equivocado ao estabelecer que há apenas um único modelo de qualidade na EaD, e que é este o modelo adotado pela Universidade Aberta do Brasil (UAB), importante projeto do próprio Ministério. O MEC diz que é apenas no formato da educação "semipresencial" (a mistura do presencial com a EaD), com atendimento regular de alunos em polos presenciais, é que existe "qualidade". Essa visão diminui as possibilidades de experimentação, de inovação e de abordagens pluralistas, fatores altamente positivos, defendidos na Lei de Diretrizes e Bases da Educação Nacional (n. 9.394/1996). Da mesma forma, representam uma atitude conservadora e fechada. Por exemplo, o MEC exige biblioteca presencial e específica para cada curso oferecida no polo, e não aceita bibliotecas digitais online, ou a possibilidade de a biblioteca central da universidade enviar livros solicitados pelos alunos. ${ }^{25}$

Em outra passagem do mesmo texto, diz o autor: "O MEC tem o direito e a liberdade de proceder assim no seu próprio programa, mas não pode obrigar toda a sociedade a fazer o mesmo". Não é preciso fazer exegese sofisticada desse texto para entender o seu exato sentido: $\mathrm{O}$ MEC é uma instituição diferente da sociedade e sem prerrogativas para interferir nos rumos dela ("tem o direito e a liberdade de proceder assim no seu próprio programa"). A ABED, nesse caso, seria a verdadeira representante da sociedade e reivindica para esta o direito de autodeterminação ("não pode obrigar toda a sociedade a fazer o mesmo"). Trata-se do radicalismo liberal não disposto a aceitar a presença do Estado como defensor e promotor do interesse público (portanto, da sociedade) e regulador da vida social. É esse o teor das indagaçóes feitas por Gomes (2009, p. 23): "Por que a EaD manteve por tanto tempo tão baixo grau de legitimidade? Por que a mão do Estado se fez tão pesada no seu controle? Se a mão do Estado era necessária, que poder moralizador tem ela para impedir a irrupção de oportunidades educacionais à mão cheia e assegurar a qualidade?". O desejo de uma "terra sem lei" 
vem travestido de combate à burocracia e à inflação legislativa. Frases como "(...) a burocracia para os credenciamentos deve ser diminuída" (Alves, 2009, p. 12), “(...) quanto mais se legisla, piores são as consequências para a qualidade da educação" (Formiga, 2009, p. 45) e "(...) o poder centralizador e controlador do Estado brasileiro pode limitar nosso avanço e com isso perdemos o potencial competitivo" (Kipnis, 2009, p. 214) não deixam dúvidas quanto a isso.

Não seria crível se não estivesse escrito, mas chega-se a sonhar com o retorno às nuas regras da vida natural (por que não dizer vida selvagem?): "Os controles centrais serão substituídos por sistemas autoorganizáveis, que se parecerão muito mais com a relação entre o homem e a natureza do que com relações institucionais" (Mesquita apud Litto, 2009, p. 17). Entretanto, sabe-se que o pensamento liberal jamais apregoou a supressão do Estado (liberais não são anarquistas). Ao contrário, o capitalismo é o modo de produção no qual a burguesia se apropriou do Estado e o utiliza para viabilizar seus projetos econômicos de vida social. Essa crítica ao Estado (à regulamentação, à burocratização) é, pois, tão somente uma forma de reivindicar as regeiras das políticas públicas para fazê-las servir aos propósitos da acumulação de capital no terreno da educação a distância.

\section{Conclusão}

As tensões motivadas pela expansão voraz da EaD no Brasil estão longe de ser equacionadas. Pelo que se viu, o ardor tende a aumentar, haja vista, por um lado, a necessidade de aumentar o controle por parte do Estado e, por outro, o acúmulo de força das instituições privadas e suas entidades representativas em razão do próprio crescimento das matrículas e do dinheiro que movimentam. A crise econômica mundial, em grande parte, atribuída à falta de regulamentação do sistema financeiro (e à consequente queda de prestígio das teses neoliberais) dará, por certo, maior legitimidade, urgência e poder ao Estado, no sentido de regulamentar as atividades educacionais, mas é impossível prever o raio de eficácia desse controle, dadas as proporções do fenômeno. Além disso, é ainda forte a ideia de que a EaD representa o futuro; que, por meio dela, se introduzem novidades tecnológicas decisivas para o sucesso da educação; que ela é a expressão societária (sociedade em rede) e pedagógica (aprender a aprender) da era do conhecimento 
etc. Como ninguém quer perder o bonde da história, poucos se interessam pela vistoria detalhada da embarcação. Mais ainda: o Brasil tem pressa em ver melhorados os índices de escolarização. A graduação, em especial, está muito aquém daquilo que se pretendia alcançar quando se elaborou o Plano Nacional de Educação. A EaD promete ser a modalidade mais revolucionária em termos de expansão das oportunidades de educação superior, com economia de tempo e de recursos. Si non è vero, è bene trovato. Esses e outros fatores poderão compor um quadro de proteção em torno de EaD, tornando-a pouco sensível às críticas que lhe são feitas de todos os lados. Se for verdade que o número de alunos de graduação matriculados quase duplicou de 2007 para 2008, como vem sendo divulgado, passando de 369.766 para $760.599,{ }^{26}$ deve-se admitir que a expansão da EaD está longe do controle e permanecerá, praticamente, imune às políticas regulatórias.

Resta saber quantos desses alunos recém-matriculados o fizeram em cursos de licenciatura, especialmente Pedagogia, e quantos buscaram Serviço Social, pois, como se viu, nesses cursos, a EaD já comandava, em 2007, de um terço para mais das matrículas registradas na graduação. Em outro texto, já referido, chamou-se a atenção para a formação de professores a distância. O Titanic está chegando perigosamente próximo ao iceberg. Em boa hora, o coro dos que alertam para o perigo está se ampliando e elevando o brado. O item 161 do Documento-Referência da CONAE 2010, por exemplo, diz: "A formação e a valorização dos profissionais do magistério devem contemplar aspectos estruturais, particularmente, e superar, paulatinamente, as soluçóes emergenciais, tais como: cursos de graduação (formação inicial) a distância (...)”. O que fará a Conferência Nacional, em 2010, com essa proposta? O que fará o Brasil com esse dilema? Quaerenti propere danda est responsio lenta!

Recebido em julho de 2010 e aprovado em agosto de 2010.

\section{Notas}

1. Entre 5 e 9 de março de 1990, realizou-se, em Jomtien, Tailândia, a Conferência Mundial sobre Educação para Todos, convocada pela UNESCO, UNICEF, PNUD e BM. A Conferência proclamou a Declaração Mundial sobre Educação para Todos, cujo subtítulo é: Satisfação das Necessidades Básicas de Aprendizagem. Impulsionados pela Conferência e pela Declaração, os países detentores do maior número de analfabetos e maiores déficits no atendimento da 
escolarização obrigatória (EFA 9: Education for All; integrantes: Brasil, Indonésia, México, China, Paquistão, Índia, Nigéria, Egito e Bangladesh) produziram planos decenais de desenvolvimento da educação. Pela Portaria n. 489, de 18 de março de 1993, o ministro da Educação, Murílio de Avellar Hingel, criou a Comissão Especial para elaborar o Plano Decenal de Educação Para Todos e deu-lhe dois meses para ultimar o trabalho. A versão preliminar do documento deveria ser debatida no âmbito de uma Semana Nacional de Educação para Todos, a ser realizada entre 10 e 14 de maio de 1993. Esse encontro, de fato, aconteceu e dele derivou o documento Compromisso Nacional de Educação para Todos, de 14 de maio de 1993. O Plano Decenal de Educação para Todos - 1993-2003, foi, em seguida, encaminhado às escolas brasileiras para ser discutido. Todos esses documentos encontram-se em: Brasil/MEC (1993).

2. Lei n. 9.131, de 24 de novembro de 1995: Institui o Conselho Nacional de Educação no lugar do Conselho Federal de Educação e define regras para a avaliação da educação superior.

Medida Provisória n. 1.477 39, de 8 de agosto de 1997, convertida na Lei n. 9.870, de 23 de novembro de 1999: Trata das mensalidades escolares, mas também define as personalidades jurídicas das mantenedoras da educação superior, prevendo a existência das que operam com fins lucrativos.

Decreto n. 2.306, de 19 de agosto de 1997: Regulamenta a organização institucional da educação superior e os atos regulatórios do Ministério da Educação.

Decreto n. 2.494, de 10 de fevereiro de 1998: Regulamente a EaD no Brasil.

Lei n. 9.649, de 27 de maio de 1998: Trata dos serviços de fiscalização das profissões e impede a União de ampliar, autonomamente, a educação profissional no Brasil.

3. Para detalhes sobre a expansão dos cursos superiores de tecnologia, ver Giolo (2006).

4. O presidente da Associação Brasileira de Educação a Distância (ABED), em 2001, queixava-se, perante a Assembléia da Entidade, que "são criados, por parte do MEC, obstáculos para a abertura de cursos a distância em nível de graduação, uma vez que o número de cursos solicitando aprovação, em 1999, era de 1.500 e atualmente são 4.000". Ata da Assembléia Geral Ordinária da ABED, de 6 de agosto de 2001. Disponível em: <http:// www2.abed.org.br/institucional.asp?.Institucional_ID=24>.

5. Sobre a EaD e a formação de professores, ver Giolo (2008).

6. Artigo 11 do Estatuto da Associação Brasileira de Educação a Distância (ABED) e artigo 11 de seu Regimento. Disponível em: <http://www2.abed.org.br/abed.asp>.

7. I Epístola de São Paulo sobre Educação a Distância, aprovada pela Assembléia Geral da ABED, em 16 de maio de 1996. Disponível em: <http://www2.abed.org.br/abed.asp>.

8. II Epístola de São Paulo sobre Educação a Distância, de 1998. Disponível em: <http:// www2.abed.org.br/abed.asp>.

9. Epístola de São Sebastião sobre Educação a Distância, s.d. Disponível em: <http:// www2.abed.org.br/abed.asp>.

10. Ata da Assembléia Geral Ordinária da ABED, de 6 de agosto de 2001. Disponível em: $<$ http://www2.abed.org.br/institucional.asp?Institucional_ID=24>.

11. Cf. Estatuto da Frente Parlamentar de Apoio à Educação a Distância, artigo 11. Disponível em: <http://www.ipae.com.br/pub/pt/re/rbead/55/materia2.htm>.

Educ. Soc., Campinas, v. 31, n. 113, p. 1271-1298, out.-dez. 2010

Disponível em <http://www.cedes.unicamp.br> 
Educação a distância: tensões entre o público e o privado

12. Cf. Estatuto da Frente Parlamentar de Apoio à Educação a Distância, artigo 11. Disponível em: <http://www.ipae.com.br/pub/pt/re/rbead/55/materia2.htm>.

13. Ver Castanheira, Biondi e Pomar (2001). A Revista da ADUSP (Associação dos Docentes da Universidade de São Paulo) fez um Dossiê sobre as 26 Fundações privadas que, em 2001, funcionavam vinculadas à USP. Esse Dossiê foi publicado na Revista da ADUSP n. 22, de março de 2001 (disponível em: http://www.adusp.org.br/revista/22/Default.htm) e na Revista da ADUSP n. 23, de setembro de 2001 (disponível em: http://www.adusp.org.br/ revista/23/Default.htm).

14. Fala do prof. Ciro Teixeira Corrêa, presidente da ADusp, à Comissão de Educação da Assembléia Legislativa de São Paulo, em 21 de novembro de 2001. Ata da 9a Reunião Ordinária da Comissão de Educação, da 3a Sessão Legislativa, da 14a Legislatura. Disponível em: <http://www.al.sp.gov.br/geral/comissoes/ata.jsp?idAta=301\&comissao= $8502 \&$ legislatura $=14>$.

15. No censo da Educação Superior do INEP, em 2000, aparecem apenas quatro IES com matrículas em EaD: UDESC (270 alunos); UNEMAT (813 alunos), UECE (299 alunos) e UfAL (300 alunos). Em 2002, a UDESC já apresentava 13.574 matrículas, subindo, em 2003, para 16.183, permanecendo, nos anos seguintes, com, aproximadamente, 13 mil matrículas, até despencar para 4.451, em 2007.

16. Excerto do voto do desembargador Luiz Cezar Medeiros, inserido no acórdão da Apelação Cível n. 2006.026340 4 e citado na argumentação da Apelação Cível n. 2008.0587874 , de 23 de junho de 2009, relatado por Newton Trisotto.

17. Portal de Canoinhas, 20 de novembro de 2008: Prefeitura e UDESC condenadas a devolver mensalidades para ex-alunos. Disponível em: <http://www.portaldecanoinhas.com.br/noticias/5974>.

18. Os cursos a distância oferecidos pela UnITINs são: Administração, Análise e Desenvolvimento de Sistemas, Ciências Contábeis, Complementação de Estudos, Fundamentos Jurídicos, Letras, Matemática, Pedagogia e Serviço Social; e os cursos presenciais são apenas dois tecnológicos: Tecnólogo em Agronegócios e Tecnólogo em Mineração.

19. Essas irregularidades são: “a) a Unitins é uma universidade pública estadual contratada por uma empresa privada para a oferta de cursos de graduação a distância; b) ausência de conexão acadêmica entre o corpo docente da UNITINS com os estudantes; c) ausência de conexão da UNITINS com os polos e centros associados; d) polos e centros associados em relação de terceirização (franquias) e quantidade significativa deles sem condiçōes e infraestrutura adequadas para um local de oferta de curso superior, isto é, locais de atendimento a estudantes sem o devido credenciamento e/ou precários; e) poucos professores para o grande número de estudantes matriculados; f) acompanhamento acadêmico aos estudantes precário, inferior ao estabelecido em padrão de qualidade publicado pelo MEC". Disponível em: $<$ http://portal.mec.gov.br/index.php?option=com_content $\&$ view=article\&id $=13374 \&$ Itemid $=924>$.

20. Publicado no Diário Oficial da União, em 26 de fevereiro de 2009, Seção 1, n. 38, p. 14.

21. Documento da ABED, publicado no JC E-mail (Jornal da Ciência, órgão da Sociedade Brasileira para Progresso da Ciência) - Notícias, n. 3.651, 28 nov. 2008.

22. Sobre isso, caberia uma pesquisa que mapeasse as lideranças sociais e políticas que o movimento estudantil produziu para o Brasil e os compromissos que suscitou nos demais estudantes que ele realmente atingiu. Essa pesquisa poderia também conjecturar que chances 
teriam essas lideranças de se constituírem como tais, caso lhe faltassem a experiência do campus universitário?

23. Publicado no JC E-mail (Notícias, n. 3.387, 9 nov. 2007).

24. Manifestação disponível em: <http://www1.folha.uol.com.br/folha/educacao/ult305u385661. shtml>. Acesso em: 10 nov. 2009.

25. Documento da ABED, publicado no JC E-mail (Notícias, n. 3.651, 28 nov. 2008).

26. Cf. JC E-mail (n. 3772, 29 maio 2009), disponível em: <http://portal.mec.gov.br/ index.php?option $=$ com_content\&view $=$ article\&id $=289 \&$ Itemid $=822>$. Acesso em $12 \mathrm{de}$ novembro de 2009>.

\section{Referências}

ABED. Estatuto da Associação Brasileira de Educação a Distância. Disponível em: <http://www2.abed.org.br/abed.asp>. Acesso em: 10 nov. 2009.

ABED. I Epistola de São Paulo sobre Educação a Distância, aprovada pela Assembléia Geral da ABED, em 16 de maio de 1996. Disponível em: <http://www2.abed.org.br/abed.asp>. Acesso em: 8 nov. 2009.

ABED. II Epistola de São Paulo sobre Educação a Distância, de 1998. Disponível em: <http://www2.abed.org.br/abed.asp>. Acesso em: 8 nov. 2009.

ABED. Epistola de São Sebastião sobre Educação a Distância, s.d. Disponível em: <http://www2.abed.org.br/abed.asp>. Acesso em: 8 nov. 2009.

ABED. Ata da Assembléia Geral Ordinária da ABED, de 6 de agosto de 2001. Disponível em: <http://www2.abed.org.br/institucional.asp? Institucional_ID=24>. Acesso em: 6 nov. 2009.

ALVES, J.R.M. A história da EaD no Brasil. In: LitTo, F.; Formiga, M. (Org.). Educação à distância: o estado da arte. São Paulo: Pearson Education do Brasil, 2009. p. 9-13.

BRASIL. Congresso Nacional. Estatuto da Frente Parlamentar de Apoio à Educação a Distância. Disponível em: <http://www.ipae.com.br/ $\mathrm{pub} / \mathrm{pt} / \mathrm{re} / \mathrm{rbead} / 55 / \mathrm{materia2}$.htm>. Acesso em: 5 nov. 2009.

BRASIL. Constituição (1988). Constituição da república Federativa do Brasil. Brasília, DF: Senado, 1988. 
Educação a distância: tensões entre o público e o privado

BRASIL. Decreto n. 2.306, de 19 de agosto de 1997. Diário Oficial da União, Brasília, DF, 20 ago. 1997.

BRASIL. Decreto n. 2.494, de 10 de fevereiro de 1998. Diário Oficial da União, Brasília, DF, 12 fev. 1998.

BRASIL. Decreto n. 5.622, de 19 de dezembro de 2005. Diário Oficial da União, Brasília, DF, 20 dez. 2005.

BRASIL. Decreto n. 6.303, de 12 de dezembro de 2007. Diário Oficial da União, Brasília, DF, 13 dez. 2007.

BRASIL. Emenda Constitucional n. 14, de 12 de setembro de 1996. Diário Oficial da União, Brasília, DF, 13 set. 1998.

BRASIL. Lei n. 9.131, de 24 de novembro de 1995. Diário Oficial da União, Brasília, DF, 25 nov. 1995.

BRASIL. Lei n. 9.394, de 20 de dezembro de 1996. Estabelece as diretrizes e bases da educação. Diário Oficial da União, Brasília, DF, 23 dez. 1996.

BRASIL. Lei n. 9.424, de 24 de dezembro de 1996. Diário Oficial da União, Brasília, DF, 12 dez. 1996.

BRASIL. Lei n. 9.649, de 27 de maio de 1998. Diário Oficial da União, Brasília, DF, 28 maio 1998.

BRASIL. Lei n. 9.870, de 23 de novembro de 1999. Diário Oficial da União, Brasília, DF, 24 nov. 1999.

BRASIL. Medida Provisória n. 1.477 39, de 8 de agosto de 1997. Diário Oficial da Uniāo, Brasília, DF, 11 ago. 1997.

BRASIL. Ministério da Educação. Instituto Nacional de Estudos e Pesquisas Educacionais (INEP). Censo da Educação Superior: 1996, 2000, 2001, 2002, 2003, 2004, 2005, 2006 e 2007. Brasília, DF: MEC/INEP, 1996-2007.

BRASIL. Ministério da Educação. Portaria Normativa n. 2, de 10 de janeiro de 2007. Diário Oficial da Uniāo, Brasília, DF, 11 jan. 2007.

BRASIL. Ministério da Educação. Portaria n. 40, de 12 de dezembro de 2007. Diário Oficial da União, Brasília, DF, 13 dez. 2007. 
BRASIL. Ministério da Educação. Portaria n. 1.047, de 7 de novembro de 2007. Diário Oficial da União, Brasília, DF, 8 nov. 2007.

BRASIL. Ministério da Educação. Portaria n. 1.050, de 7 de novembro de 2007. Diário Oficial da União, Brasília, DF, 8 nov. 2007.

BRASIL. Ministério da Educação. Portaria n. 1.051, de 7 de novembro de 2007. Diário Oficial da União, Brasília, DF, 8 nov. 2007.

BRASIL. Ministério da Educação. Plano Decenal de Educação para Todos. Brasília, DF: MEC, 1993.

CASTANHEIRA, A.; BIONDI, A.; POMAR, P.E.R. Fundações demais, transparência de menos. Revista da ADUSP, são Paulo, n. 22, mar. 2001. Disponível em: <http://www.adusp.org.br/revista/22/Default.htm>. Acesso em: 6 nov. 2009.

DOCUMENTO DA ABED. In: JC E mail (Jornal da Ciência, órgão da Sociedade Brasileira para Progresso da Ciência), Notícias, n. 3.651, 28 nov. 2008.

FORMigA, M. A terminologia da Ead. In: Litto, F.; Formiga, M. (Org.). Educação a distância: o estado da arte. São Paulo: Pearson Education do Brasil, 2009. p. 39-46.

GIOLO, J. A educação tecnológica superior no Brasil: os números de sua expansão. In: Moll, J.; Savegnani, P. (Org.). Universidade e mundo do trabalho. Brasília, DF: INEP, 2006. p. 109134.

GIOLO, J. A educação à distância e a formação de professores. Educação \& Sociedade, Campinas, v. 29, n. 105, p. 1211 1234, set./dez. 2008.

GOMES, C.A.C. A legislação que trata da EaD. In: LitTo, F.; FormiGA, M. (Org.). Educação a distância: o estado da arte. São Paulo: Pearson Education do Brasil, 2009. p. 21-27.

JC E-MAIL (Jornal da Ciência, órgão da Sociedade Brasileira para Progresso da Ciência), Notícias, n. 3.387, 9 nov. 2007.

JC E-MAIL (Jornal da Ciência, órgão da Sociedade Brasileira para Progresso da Ciência), n. 3772, 29 maio 2009.

KIPNIS, B. Educação superior à distância no Brasil: tendências e perspectivas. In: LiTTO, F.; FormigA, M. (Org.). Educação a distância: 
o estado da arte. São Paulo: Pearson Education do Brasil, 2009. p. 209-214.

LITTO, F.M. Associação Brasileira de Educação a Distância (ABED) manifesta se sobre decisões do MEC para a modalidade de ensino. JC E-mail, n. 3651, 28 nov. 2008: Disponível em: <http:// www.jornaldaciencia.org.br/Detalhe.jsp?id=602110>. Acesso em: 5 nov. 2009.

LITTO, F.M. O atual cenário internacional da EaD. In: LiTTO, F.; Formiga, M. (Org.). Educação a distância: o estado da arte. São Paulo: Pearson Education do Brasil, 2009. p. 114-20.

SÃO PAULO. Assembleia Legislativa. Ata da 9a Reunião Ordinária da Comissão de Educação, da $3^{a}$ sessão legislativa, da $14^{a}$ legislatura, de 21 de novembro de 2001. Disponível em: <http://www.al.sp.gov.br/ geral $/$ comissoes/ata.jsp?idAta301\&comissao $=8502 \&$ legislatura $=14>$ Acesso em: 6 nov. 2009. 